\title{
OBJETO Y CONTENIDO DE LOS DERECHOS FUNDAMENTALES: PRESUPUESTOS \\ E IMPLICACIONES DE UNA NUEVA DIFERENCIACIÓN DOGMÁTICA
}

\author{
JORGE ALGUACIL GONZÁLEZ-AURIOLES \\ Profesor Ayudante de Derecho Constitucional \\ Universidad Nacional de Educación a Distancia
}

\author{
SUMARIO \\ I. Presupuestos del debate. \\ II. Objeto y contenido en la dimensión sub- \\ jetiva de los derechos. \\ III. Objeto y contenido en la dimensión ob- \\ jetiva de los derechos. \\ IV. La defensa de la dogmática clásica. \\ V. Recapitulación.
}

Recientemente Villaverde ha defendido la conveniencia de diferenciar en la dogmática de los derechos entre objeto y contenido. ${ }^{1}$ Por objeto del derecho entiende lo que éste protege; el contenido del derecho alude a cómo protege el derecho este contenido ${ }^{2}$. Una diferenciación similar ha sido objeto de debate en Alemania, el objeto del derecho se define aquí como el ámbito material y vital del derecho (Sach - und Lebensbereich); el contenido del derecho es el contenido de garantía (Gewährleistungsgehalt). Laten tras este debate, que se apoya en cierta jurisprudencia constitucional reciente, discrepancias sobre la interpretación amplia o restrictiva de la protección que incorporan los derechos, con

1 VILLAVERDE, I, "Concepto, contenido, objeto y límites de los derechos fundamentales", La democracia constitucional. Estudios en homenaje al Profesor Francisco Rubio Llorente, Madrid: Centro de Estudios Políticos y Constitucionales, 2002, pp. 317-360.

2 VILLAVERDE, I, "Concepto, contenido, objeto y límites de los derechos fundamentales", op. cit., p. 332.

UNED. Teoria y Realidad Constitucional, núm. 18, 2006, pp. 305-319. 
un evidente alcance sobre la aplicación del principio de proporcionalidad y la naturaleza del contenido esencial. Esta discusión evidencia también diferentes percepciones sobre el papel de los derechos en el Estado constitucional y, por tanto, diversas sensibilidades a la hora de concebir el vigente constitucionalismo.

Una concepción liberal clásica, cuya vigencia bajo la Ley Fundamental de Bonn fue defendida inicialmente por Forsthoff, entiende los derechos fundamentales como meros derechos de defensa frente al Estado; son así exclusivamente prohibiciones de acción del poder público: aseguran un ámbito de libertad al ciudadano frente al Estado. Su nota característica es vincular a todos los poderes públicos, especialmente al legislador, que aparecería fundamentalmente como enemigo de los derechos. El contenido esencial de éstos sería aquel ámbito del derecho que la ley no podría restringir; el Tribunal Constitucional protege tal contenido esencial. Así se asegura de forma escrupulosa un ámbito de discrecionalidad al legislador democrático, al configurar a la jurisdicción constitucional como una jurisdicción de límites; y se marcan con claridad las fronteras que el legislador no puede traspasar. Pero tampoco el Tribunal Constitucional puede extender sus poderes mediante la aplicación, por ejemplo, del principio de proporcionalidad para controlar la limitación de los derechos fundamentales por parte del legislador; debe ceñirse a comprobar que no vulnera el contenido esencial del derecho. Si la tarea del legislador es precisamente la de ponderar bienes y valores, también en la eventual limitación de los derechos, tal ponderación no puede ser sustituida por el Tribunal Constitucional, so pena de otorgarle un poder desmesurado, incontrolable y que contraviene por lo tanto el principio democrático ${ }^{3}$.

Ahora bien, esta concepción de los derechos se encuentra con dificultades en el vigente constitucionalismo, mediado por la pluralidad y el conflicto, y que no puede permanecer ajeno a los procesos políticos y sociales en que arraiga su fuerza normativa ${ }^{4}$. Se evidencia así como imprescindible la extensión de la efectividad de los derechos fundamentales a todos los ámbitos de la realidad social. Esto supone que el legislador asume una nueva tarea, la de proteger y actuar como garante de esos derechos. Si los derechos fundamentales no son

3 Forsthoff alerta sobre los riesgos de la nueva interpretación impuesta por el constitucionalismo contemporáneo en Zur Problematik der Verfassungsauslegung, 1961. En su opinión, únicamente el positivismo jurídico puede actuar como barrera frente a la imposición antidemocrática de opiniones e ideologías ("Die Umbildung des Verfassungsstaates", Rechtsstaat im Wandel. Verfassungsrechtliche Abhandlungen. Festschrift für Carl Schmitt 70 Geburtstag, Berlín, 1959). Una condensación de sus ideas puede encontrarse en FORSTHOFF, E, Der Staat der Industrielgesellschaft, 1971 (hay versión en castellano: El Estado de la Sociedad Industrial, Madrid: Instituto de Estudios Políticos, 1975). Más recientemente, asume matizadamente la exposición clásica de Forsthoff SCHLINK, B, "Freiheit durch Eingriffsabwehr - Rekonstruktion der klassischen Grundrechtsfunktion", EuGRZ1984, p. 462; cfr. PIEROTH, B; SCHLINK, B, Grundrechte. Staatsrecht Heidelberg: Müller Verlag, 2005, pp. 65-70.

4 LÓPEZ PINA, A; GUTIÉRREZ GUTIÉRREZ, I, Elementos de Derecho Público, Madrid. Barcelona: Marcial Pons, 2002, p. 111. 
sólo derechos subjetivos, sino también principios objetivos que informan todo el ordenamiento jurídico, generan tareas al Estado.

Tales cometidos deben dirigirse en un Estado democrático por medio de la ley, cuya posición en el ordenamiento jurídico, que trae causa ya no sólo de su esencial democraticidad, sino también de su función de garantía de los derechos, convierte en especialmente problemática su relación con éstos. Ciertamente, el legislador no dispone del contenido jurídico del derecho fundamental; pero las conductas genéricamente garantizadas en tales derechos precisan de desarrollo y concretización, que corresponde primariamente a la ley. Como observa Villaverde, «al legislador le corresponde llenar el espacio entre la estructura abierta y abstracta del derecho fundamental y su concreción en reglas jurídicas " ${ }^{5}$. Por lo demás, en la actual sociedad pluralista los supuestos de limitación y colisión entre derechos son múltiples. No es ya que la ley pueda ser un complemento normativo para concretar el objeto, el contenido y los límites del derecho; es que los derechos precisan de la ley para asegurar su normatividad en las actuales condiciones. La tensión derechos fundamentales - legislador, constitutiva del constitucionalismo desde sus inicios, continúa siendo el centro de los conflictos en la actualidad. Las nuevas funciones del legislador hacen necesario asegurar que al desarrollo democrático de los derechos no se imponga la hermenéutica de la jurisdicción constitucional salvo para trazar límites. Pero, a su vez, la nueva posición que asumen los derechos exige una paralela revalorización del legislador como su garante; de lo contrario, pueden generarse falsas expectativas de derechos que, sin embargo, carecen de garantía y por lo tanto se encuentran huérfanos de normatividad.

El debate dogmático, en fin, no se comprende sin conocer el sentido y la relevancia que alcanzan los derechos fundamentales en Alemania (1). El extraordinario desarrollo que adquieren desde la segunda mitad del siglo pasado no se encuentra exento de críticas ${ }^{6}$. Nos encontramos en la actualidad con dos tipos de cuestionamientos. El primero se centra en el riesgo que el desarrollo de los derechos fundamentales tiene para el principio democrático. La necesidad de dotar de un espacio de libertad creadora al legislador hace que Böckenförde considere necesario replantearse la dogmática de los derechos fundamentales, y que postule ahora la conveniencia de diferenciar entre ámbito material y vital del derecho (Sach - und Lebensbereich), contenido de garantía (Gewährleistunngsgehalt) e intervención (Eingriff) en el derecho (2). Tal propuesta dogmática es asumida por Hoffmann-Riem, si bien a partir de fundamentos diversos: ciertamente, el nuevo constitucionalismo sitúa a los derechos fundamentales en una posición central; pero si su eficacia depende en buena medida del legislador, y a tal revalorización de los derechos no le co-

5 VILLAVERDE, I, "Concepto, contenido, objeto y límites de los derechos fundamentales", $L a$ democracia constitucional. Estudios en homenaje al Profesor Francisco Rubio Llorente, Madrid: Centro de Estudios Políticos y Constitucionales, 2002, p. 352.

6 Un resumen de la polémica se encuentra en GUTIÉRREZ GUTIÉRREZ, I, “Teoría y Realidad Constitucional en Alemania", Teoría y Realidad Constitucional n 1, 1998, pp. 200-2004. 
rresponde una revalorización de la ley, se corre el riesgo de caer en un constitucionalismo generador de falsas expectativas (3). Kahl polemiza con Böckenförde y Hoffmann-Riem. Niega la oportunidad de la nueva distinción y defiende como único concepto válido en este contexto el de contenido esencial del derecho, que lo protege del legislador; no cabe tampoco, en su opinión, apelar al principio de proporcionalidad, pues puede otorgar al Tribunal Constitucional un poder incontrolable. Los argumentos esgrimidos por Kahl son replicados por Hoffmann-Riem (4). Las tesis expuestas nos darán pie para formular algunas ideas finales sobre el estado de la dogmática de los derechos fundamentales en Alemania y en España (5)

\section{PRESUPUESTOS DEL DEBATE}

La denominada dimensión objetiva de los derechos fundamentales es quizá la mayor aportación del constitucionalismo germano a la reciente historia constitucional europea. Lógica reacción al período vivido en Alemania de desprecio a los derechos humanos, el nuevo orden surgido tras la Segunda Guerra Mundial debía partir del reconocimiento del valor absoluto de la dignidad humana y de la garantía de los derechos fundamentales ${ }^{7}$. Como observa Wahl, el desarrollo del constitucionalismo alemán posterior a la Segunda Guerra Mundial es el claro ejemplo de cómo la transición de una dictadura a un orden constitucional únicamente se puede realizar a partir del "nuevo nacimiento del orden jurídico sobre el espíritu de los derechos fundamentales ${ }^{8}$. El reconocimiento de la dimensión objetiva de los derechos fundamentales sólo pretende asegurar este desarrollo.

Los condicionamientos históricos explican que el Tribunal Constitucional alemán asumiera en el nuevo orden constitucional una posición de destacada prevalencia ${ }^{9}$. La sentencia Lüth del Tribunal Constitucional alemán de 15 de enero de 1958 (Lüth-Entscheidung), una de sus resoluciones más importantes, formula la nueva comprensión de los derechos fundamentales y de la propia función del Tribunal en el nuevo orden ${ }^{10}$. Cabe destacar al menos dos consecuencias de la sentencia. En primer lugar, extiende el propio ámbito de competencia del Tribunal Constitucional, porque el espacio de actuación de los de-

7 Cfr. WAHL, R, “Die objektiv-rechtliche Dimension der Grundrechte im internationalen Vergleich", MERTEN/PAPIER (eds), Handbuch der Grundrechte in Deutschland und Europa. Band I. Entwicklung und Grundlagen, CF Müller, 2003, pp. 746 y ss.

8 WAHL, R, "Die objektiv-rechtliche Dimension der Grundrechte im internationalen Vergleich", op. cit., pp. 746 y 755 y ss.

9 Para Wahl no existía otra alternativa al activismo del Bundesverfassungsgericht, WAHL, R., "Die objektiv-rechtliche Dimension der Grundrechte im internationalen Vergleich", op. cit., pág 757.

10 En el discurso que realizó Gerhard Casper con motivo de los cincuenta años del Bundesverfassungsgericht, destacó que, si tuviera que llevarse una única sentencia del Tribunal a una isla desierta, sería precisamente la Lüth-Entscheidung la que se llevaría (citado por WAHL, R, "Die objektiv-rechtliche Dimension der Grundrechte im internationalen Vergleich", op. cit., pág 747). 
rechos fundamentales que garantiza no se reduce a la relación entre Estado-individuo, sino que se extiende también a las relaciones entre particulares. En segundo lugar, aporta una nueva comprensión de los derechos: no son sólo derechos subjetivos sino valores objetivos que informan todo el ordenamiento jurídico; expresa así el nacimiento de todo el nuevo orden jurídico sobre la base de la Ley Fundamental, y en concreto de los derechos fundamentales.

La dimensión objetiva de los derechos fundamentales impone la comprensión de todo el ordenamiento a partir de éstos. Ello tiene varias consecuencias $^{11}$. Entre las que puede citarse, en primer lugar, el efecto irradiación de los derechos sobre todo el ordenamiento; especial consideración merece, por la novedad que supone, el reconocimiento de la eficacia de los derechos fundamentales también en las relaciones entre particulares. En segundo término, la obligación del Estado de proteger los derechos fundamentales, que generan tareas al Estado y, en particular, el deber de garantizar los derechos a través de un procedimiento adecuado. Wahl alude en tercer lugar al surgimiento de específicos derechos de prestación como consecuencia de esta dimensión objetiva.

Esta nueva comprensión de los derechos no estuvo exenta de crítica desde los primeros momentos. Forsthoff advierte de los excesos a que puede llevar un desarrollo desmedido de los derechos fundamentales, alegando la autonomía de otras ramas del Derecho y el libre desenvolvimiento del orden jurídico. Para este autor, la Ley Fundamental como norma jurídica impone en su manejo sujetarla a ciertos condicionamientos técnicos que aseguren la precisión y el rigor; en su opinión, la nueva concepción de los derechos fundamentales, que ya se desprendía de la teoría de la integración de Smend, sobrepasa los límites de la Constitución formal y conduce con ello a la indeterminación y a la inseguridad jurídica. La desformalización de la Constitución, al introducir elementos materiales y sustantivos, va de la mano del desarrollo del Estado judicial, en el que el Tribunal Constitucional ocupa un papel principal; se produce con ello una transformación constitucional de gran calado. ${ }^{12}$ Más recientemente, Böckenförde formula también reservas al desarrollo de la doble dimensión de los derechos fundamentales: el protagonismo que concede al Bundesverfassungsgericht y en general a los jueces en la protección de los derechos fundamentales puede suponer el tránsito de un Estado constitucional democrático a un Estado constitucional judicial ${ }^{13}$. Las críticas se articulan a partir de la compatibilidad de tal dogmática con el principio democrático; pero también, como veremos, con la propia normatividad de los derechos fundamentales.

En cualquier caso, esta doble dimensión de los derechos ha sido asumida en general por la doctrina alemana. Konrad Hesse impulsó desde un comienzo

11 WAHL, R., "Die objektiv-rechtliche Dimension der Grundrechte im internationalen Vergleich", op. cit., p. 750.

12 FORSTHOFF, E., "Die Umbildung des Verfassungsgesetzes", BARION, H (ed), Festschrift Carl Schmitt zum 70 Geburtstag, Berlin, 1959.

13 BÖCKENFÖRDE, W, "Grundrechte als Grundsatznormen. Zur gegenwärtigen Lage zur Grundrechtsdogmatik", Staat, Verfassung, Demokratie, Frankfurt am Main, 1991, pp. 186 ss. 
tal concepción ${ }^{14}$. Su discípulo Hollerbach había replicado expresamente las tesis de Forsthoff, al rechazar la reducción y desnaturalización de la Constitución a una serie de técnicas jurídicas de organización del poder ${ }^{15}$ : la Constitución dispone de un contenido material determinado por ciertos valores con pretensión de normatividad ${ }^{16}$. Y la Constitución material no se encuentra en contraposición con la Constitución formal; ambas se complementan ${ }^{17}$. La tesis de Peter Häberle, otro discípulo de Honrad Hesse, se articula precisamente a partir de la defensa de esta doble dimensión de los derechos fundamentales ${ }^{18}$.

También Wahl encuentra en la doble dimensión de los derechos fundamentales la forma de asegurar la normatividad de la Constitución y el asentamiento de todo el orden jurídico alemán en los valores constitucionales ${ }^{19}$. La normatividad de la Constitución ${ }^{20}$ trae causa de un largo proceso en el que ciertas decisiones del Bundesverfassungsgericht desempeñan gran importancia; entre ellas destaca la Lüth-Entscheidung. No extraña que los autores que muestran una especial sensibilidad por las posibilidades de realización de los postulados constitucionales, esto es, por la realización efectiva de la Constitución y por su eficacia normativa, sean los que hayan defendido con más intensidad esta doble dimensión de los derechos fundamentales.

\section{OBJETO Y CONTENIDO EN LA DIMENSIÓN SUBJETIVA DE LOS DERECHOS}

Böckenförde reacciona frente a lo que considera una desviación en la dogmática alemana de los derechos fundamentales surgida de su interpretación y aplicación por la jurisprudencia. El reto consiste, en su opinión, en re-

14 Ya desde la primera edición de su manual de Derecho Constitucional, Grundzüge des Verfassungsrechts der Bundesrepublick Deutschland, 1 ed. 1967, pp. 110 ss.

15 HOLLERBACH, A., "Auflösung der rechtsstaatlichen Verfassung? Zu Ernst Forsthoffs Abhandlung "Die Umbildung des Verfassungsgestzes" in der Festschrift für Carl Schmitt", Archiv des Öffentliches Rechts Heft 1, 1960, p. 249.

16 HOLLERBACH, A., "Auflösung der rechtsstaatlichen Verfassung? Zu Ernst Forsthoffs Abhandlung "Die Umbildung des Verfassungsgestzes" in der Festschrift für Carl Schmitt", op. cit, p. 254.

17 HOLLERBACH, A., "Auflösung der rechtsstaatlichen Verfassung? Zu Ernst Forsthoffs Abhandlung "Die Umbildung des Verfassungsgestzes" in der Festschrift für Carl Schmitt", op. cit, p. 251.

18 HÄBERLE, P., Die Wesensgehaltgarantie des Artikel 19. Abs. 2, Karlsruhe: CF Müller, 1962. Existe versión al castellano de esta primera edición realizada por Joaquín Brage Camazano, $L a$ garantía del contenido esencial de los derechos fundamentales en la Ley Fundamental de Bonn, Madrid: Dykinson, 2005. La tercera edición de la tesis de Häberle, sensiblemente ampliada por el propio autor, es traducida parcialmente por César Landa, La libertad fundamental en el Estado constitucional, Lima: Fondo Editorial de la Pontificia Universidad Católica del Perú, 1997.

19 WAHL, R., “Die objektiv-rechtliche Dimension der Grundrechte im internationalen Vergleich", op. cit., pág 747.

20 WAHL, R., "Der Vorrang der Verfassung”, WAHL, R, Verfassungstaat, Europäisierung, Internationalisierung, Frankfurt am Main: Suhrkamp, 2003, pp. 121-160, "Der Vorrang der Verfassung und die Selbständigkeit des Rechts", Verfassungstaat, Europäisierung, Internationalisierung, Frankfurt am Main: Suhrkamp, 2003, pp. 161-187. 
cuperar una dogmática clásica que ofrezca seguridad y confianza en la aplicación de los derechos, frente a la actual dogmática que reposa desproporcionadamente en la interpretación subjetiva y arbitraria. En 1979, el Tribunal Constitucional alemán ${ }^{21}$, extiende excepcionalmente la aplicación de los límites inmanentes a todos los derechos ${ }^{22}$. El desarrollo de la propia jurisprudencia constitucional ha tendido a generalizar lo que al principio se configuró como una excepción. El análisis y la crítica de la situación vigente le permiten mostrar una nueva estructura dogmática y defenderla frente a posibles objeciones ${ }^{23}$.

La estructura y el contenido de los derechos han sido articulados tradicionalmente por las ideas de ámbito de protección (Schutzbereich) e intervención (Eingriff). Para explicar qué ha de entenderse por estos dos conceptos, Böckenförde se remite a lo expuesto por Pieroth y Schlink en su manual. El concepto de ámbito de protección (Schutzbereich) contiene para estos autores dos momentos: uno descriptivo y otro normativo. El momento descriptivo comprende el ámbito o espacio en el que el derecho fundamental se extiende o instala. El momento normativo abarca la protección que el derecho otorga a este espacio en el que se extiende ${ }^{24}$. El elemento crucial en esta dogmática es la justificación de la intervención (Eingriffsrechtsfertigung) ${ }^{25}$. Tal intervención no es problemática en los derechos sometidos a reserva de ley, pues la propia Ley Fundamental atribuye la posibilidad al legislador, que debe hacer uso de ella no de forma arbitraria, sino justificando su intervención. El problema surge al pretender justificar los límites a los derechos fundamentales que la Ley Fundamental reconoce sin reserva de ley.

Como explica el propio Böckenförde, la distinción entre derechos sometidos a reserva de ley y derechos no sometidos a tal reserva obedece a la misma causa que suscita la incorporación de un contenido esencial de los derechos fundamentales: la desconfianza frente al legislador. Por ello no existe en la Ley Fundamental una reserva general de ley que permita limitar todos los derechos, sino sólo reservas específicas en relación con derechos fundamentales concretos. Se entiende así que existen unos derechos que gozan de un valor tal que en ningún caso podría el legislador intervenir sobre ellos: son los derechos no sometidos a reserva de ley. El objetivo es asegurar con especial intensidad la libertad que el derecho garantiza frente al legislador. Entre estos derechos destaca la libertad religiosa y la libertad de culto (apartados primero y segundo del artículo 4 LF), la libertad artística y científica, investigadora y de enseñanza (artículo 5.3 LF)

21 BverfGE, 28, 243.

22 BÖCKENFÖRDE, H. W., "Schutzbereich, Eingriff, verfassungsinmanente Schranke. Zur Kritik gegenwärtiger Grundrechtsdogmatik", Der Staat, 2003, pp. 172, 173.

23 BÖCKENFÖRDE, H. W., "Schutzbereich, Eingriff, verfassungsinmanente Schranke. Zur Kritik gegenwärtiger Grundrechtsdogmatik", Der Staat, 2003, p. 165.

24 PIEROTH, B; SCHLINK, B, Grundrechte. Staatsrecht II, Heilderberg: Müller Verlag, 2005, pp. 51-53.

25 BÖCKENFÖRDE, H. W., "Schutzbereich, Eingriff, verfassungsinmanente Schranke. Zur Kritik gegenwärtiger Grundrechtsdogmatik", Der Staat, 2003, pp. 165-168. 
y el derecho de asociación (artículo $9 \mathrm{LF})^{26}$. Con respecto a estos derechos, el legislador sólo puede configurar su ámbito de protección, pero no limitarlo.

Para justificar que los derechos fundamentales sin reserva de ley puedan ser limitados aparecen los denominados limites inmanentes, que traen causa exclusivamente de la interpretación constitucional. Se trata de supuestos en los que el derecho protege un ámbito tan extenso que no parece concebible su garantía ilimitada. Por eso se basan en la interpretación sistemática de la Constitución y pueden servir para reducir el alcance del derecho en cuestión. Ciertamente, estos límites inmanentes pueden ser desarrollados por el legislador, de modo que legitiman limitaciones legales de derechos fundamentales sin reserva de ley, pero pueden aplicarse también de forma directa, sin mediación del legislador. Otorgan así al juez que los invoca un poder, a juicio de Böckenförde, incontrolable, con evidentes repercusiones sobre la seguridad jurídica y el equilibrio de poderes. Aparece así, junto a la reserva de ley, una especie de intervención directa del juez en los derechos.

Con todo ello se desvanece la razón de ser de los derechos fundamentales sin reserva de ley: ambos tipos de derechos quedan sometidos al mismo régimen, los derechos sin reserva de ley pueden limitarse tan fácilmente como los derechos sometidos a reserva de ley $^{27}$. La nueva fase que a su juicio tergiversa la dogmática tradicional de los derechos comienza en 1970, cuando cierto desarrollo jurisprudencial tiende a suprimir la diferenciación entre derechos con reserva de ley y derechos sin reserva de ley.

Para Böckenförde, sólo una nueva dogmática de los derechos puede recuperar la racionalidad perdida. Apela al efecto a una nueva diferenciación anteriormente sugerida por Wahl. Éste distingue entre ámbito material y vital del derecho (Sach - und Lebensbereich), contenido de garantía (Gewäbrleistungsinhalt) e intervención y límites (Eingriff und Shranken). Para Böckenförde, es decisiva la diferenciación entre el ámbito vital del derecho y el contenido de garantía. La división realizada en la dogmática anterior en el ámbito de protección (Schutzbereich) entre los momentos descriptivo y normativo se concreta de forma clara y rigurosa mediante la nueva propuesta. El ámbito vital del derecho evoca el interés o bien jurídico protegido, el contenido de garantía alude a la específica extensión de la garantía normativa de este bien jurídico ${ }^{28}$. Este contenido de garantía, que debe indagarse de forma independiente en cada derecho, no puede definirse de forma abstracta a partir del solo texto de la Constitución; debe identificarse para los casos concretos.

Böckenförde ofrece varios ejemplos prácticos que prueban la pertinencia de la diferenciación dogmática. En el primero, un tribunal debe juzgar, en el

26 BÖCKENFÖRDE, H. W., "Schutzbereich, Eingriff, verfassungsinmanente Schranke. Zur Kritik gegenwärtiger Grundrechtsdogmatik", Der Staat, 2003, pág 171.

27 BÖCKENFÖRDE, H. W., "Schutzbereich, Eingriff, verfassungsinmanente Schranke. Zur Kritik gegenwärtiger Grundrechtsdogmatik", Der Staat, 2003, p. 169, 170.

28 WAHL, R, "Freiheit der Wissenschaft als Rechtsproblem", Freiburger Universitätsbläter, Heft 95, 1987, pp. 19, 29-34. 
seno de un procedimiento de extradición, si la actividad desarrollada por un grafitero puede ser considerada antijurídica. El tribunal acepta tal actividad como integrante de la libertad artística; el problema es que ha invadido el derecho de propiedad. Distingue el tribunal el ámbito vital del derecho, la libertad de desarrollar la expresión artística, de su contenido de garantía, que no se extiende a la invasión por tal libertad del derecho de propiedad. Otro ejemplo puede encontrarse en la sentencia del Tribunal Constitucional alemán sobre el Tratado de Mastrique. El artículo 38 de la Ley Fundamental de Bonn comprende un ámbito vital amplio: los diputados del Bundestag, que representan a la totalidad del pueblo y son elegidos por sufragio universal, gozan de competencias legislativas, financieras y de control. Pero la autorización del artículo 23.1 LF de transferir competencias a la Unión Europea determina de forma restrictiva el contenido de protección del derecho protegido por este precepto. La pertinencia de la nueva dogmática puede comprenderse también al analizar de forma abstracta derechos fundamentales particulares; por ejemplo, la libertad de culto, un derecho sin reserva de ley proclamado en el artículo 4.2 LF. A la libertad de creer o de no creer se une el derecho del creyente a comportarse conforme a los preceptos que marca su religión. Este último derecho necesita ser compatibilizado con otros derechos y bienes constitucionales; en definitiva, exige configurar son precisión su contenido de garantía y sus límites.

Böckenförde reconoce que, frente a la nueva dogmática de los derechos, cabe alegar que lo único que logra es desplazar el problema, no solucionarlo: las cuestiones que antes se trataban bajo el aspecto de la intervención en el derecho son trasladadas ahora al ámbito de su contenido de garantía. De este modo, la preservación de los derechos no sometidos a reserva de ley y, por lo tanto, sin posibilidad de intervención, sería solo aparente. Una segunda objeción consistiría en que la nueva dogmática podría petrificar el contenido de los derechos, al depender sólo de la interpretación y no del legislador. El vigente constitucionalismo democrático, sin embargo, configura a la Constitución como un código abierto cuya concretización corresponde al legislador, al que corresponde en cada caso articular jurídicamente tal contenido de garantía. Por último, Böckenförde señala que aquellos ámbitos de libertad no comprendidos en el contenido de garantía de los derechos no se encuentran por ello huérfanos de protección constitucional; la encuentran en el genérico derecho al libre despliegue de la personalidad, consagrado en el artículo 2 LF.

En conclusión, para Böckenförde el legislador democrático es el encargado de configurar los derechos y no el juez mediante técnicas interpretativas difíciles de reducir a criterios objetivos. Los derechos fundamentales cuyo reconocimiento constitucional no está sometido a reserva de ley quedan sujetos sólo al límite elemental de que su ejercicio no resulte dañino; el legislador puede o incluso debe precisarlo, de modo que al juez le resulte innecesario recurrir de modo inmediato a la Constitución para trazar tal límite. Los derechos fundamentales con reserva de ley pueden ser configurados y limitados normalmente por el legislador; el contenido de protección del derecho se defiende en último extremo aplicando el principio de proporcionalidad. La nueva dog- 
mática, reconoce Böckenförde, sirve para estructurar los derechos considerando exclusivamente su dimensión subjetiva; no serviría, sin embargo, para explicar su configuración como principios objetivos del ordenamiento jurídico ${ }^{29}$.

\section{OBJETO Y CONTENIDO EN LA DIMENSIÓN OBJETIVA DE LOS DERECHOS FUNDAMENTALES}

Hoffmann-Riem asume la propuesta de Böckenförde como solución al problema que, a su juicio, existe en la actual dogmática de los derechos fundamentales. Éste no está sin embargo centrado, en su opinión, en la falta de seguridad jurídica y en la tergiversación de la división de poderes, sino en el riesgo de falta de normatividad de los derechos fundamentales. La dogmática vigente debe cuidarse de no caer en una retórica de los derechos que carezca de eficacia real.

De un lado, al extender el contenido de protección de los derechos pueden multiplicarse también sus límites; la consecuencia es que en realidad se de una menor protección del derecho ${ }^{30}$. En efecto, la dinámica de la moderna sociedad pluralista no sólo ha contribuido en ciertos casos a extender el ámbito de protección de los derechos, también ha servido para justificar los límites de derechos tradicionalmente considerados ilimitables. Así, por ejemplo, la libertad de pensamiento y de conciencia (artículo $4 \mathrm{LF}$ ), que garantiza el comportamiento conforme a las directrices del credo que se profesa, puede resultar especialmente problemática en la actual sociedad multicultural. Difícilmente cabe proteger sacrificios animales o incluso humanos que traigan causa de un credo religioso; es preciso entonces encontrar una forma de limitar tales prácticas. En la garantía del derecho de reunión (artículo 9.3 LF) deben coordinarse también diferentes intereses a menudo contrapuestos; también la libertad de investigación (artículo 5.3 LF) exige regulaciones específicas, por ejemplo en lo que respecta a la investigación con embriones.

Por lo demás, no cabe ejercer los derechos fundamentales sin referencia a una realidad concreta que lo posibilite: la libertad de culto sólo puede ejercerse allí donde haya convicciones religiosas y se practiquen ritos, sólo cabe ejercer la libertad de asociación donde exista participación democrática en forma de asociaciones. Las conductas genéricamente garantizadas en un derecho fundamental siempre se dan en la realidad como algo concreto. La especificidad de cada supuesto impone la necesidad de concretar el objeto, el contenido y los límites del derecho abstractamente configurado en la Constitución; tal labor ha de articularse a través de la ley. Si el Derecho no debe desprenderse de la realidad, los poderes públicos deben contribuir también a asegurar la liber-

29 BÖCKENFÖRDE, H. W., "Schutzbereich, Eingriff, verfassungsinmanente Schranke. Zur Kritik gegenwärtiger Grundrechtsdogmatik", Der Staat, 2003, pág 192.

30 HOFFMANN-RIEM, W., "Enge oder weite Gewährleistungsgehalte der Grundrechte?", BAUERLE (ed), Haben wir wircklich Recht?, 2003, p. 54. 
tad; la garantía de los derechos se realiza a través de su concretización y del establecimiento de sus límites ${ }^{31}$. De ahí que la libertad no sea sólo libertad frente al Estado; éste tiene también la tarea de asegurar la libertad real. Además, en la compleja sociedad de masas los derechos no se desarrollan aisladamente; surgen de continuo supuestos de conflicto entre ellos, y es preciso entonces hallar una concordancia práctica. Ésta únicamente se logra al configurar los derechos por medio de la ley.

Por lo demás, corresponde al legislador precisar y desarrollar conceptos jurídicos indeterminados, por ejemplo el concepto de domicilio (artículo 13 $\mathrm{LF})^{32}$. Los retos que impone la actual sociedad de la información imponen también una regulación pormenorizada. El legislador configura así los derechos, mediante la delimitación de su ámbito de protección ${ }^{33}$; en ese contexto cobra sentido recurrir a la propuesta de Böckenförde de diferenciar con nitidez un ámbito material y vital del derecho y un contenido de garantía. La configuración legislativa, que permite a los derechos alcanzar efectividad real, se lleva a cabo a través del denominado contenido de garantía. En definitiva, para reforzar los derechos deben extenderse las posibilidades de configuración del legislador a través de la determinación de su contenido de garantía.

\section{LA DEFENSA DE LA DOGMÁTICA CLÁSICA}

Las propuestas de Böckenförde y Hoffmann-Riem conducen en opinión de Kahl a la inseguridad y a la quiebra del sentido de los derechos y de su garantía. Para él, la dogmática tradicional es la única que puede ofrecer seguridad jurídica y rigor. La teoría de los derechos se articula a partir de una nítida diferenciación entre el ámbito de protección, la intervención en el derecho y la justificación constitucional de tal intervención. El constituyente puede establecer un ámbito de protección amplio o reducido. Un ejemplo de ámbito de protección amplio lo tenemos en el derecho de reunión pacífica y sin armas (artículo 8.1 LF); la libertad del arte y la ciencia del artículo 5.3 LF tiene un ámbito de protección reducido. A través de las diferentes interpretaciones constitucionales, realizadas principalmente por el Tribunal Constitucional, se establecen los límites a los derechos; éstas deben tener en cuenta la sistemática de la Constitución, el sentido del concreto derecho, su formación histórica, etc ${ }^{34}$.

La jurisprudencia reciente que asume la nueva dogmática ha supuesto a su entender una reducción del ámbito de protección del derecho; se ha pasado, en

31 HOFFMANN-RIEM, W., "Enge oder weite Gewährleistungsgehalte der Grundrechte?", BAUERLE (ed), Haben wir wircklich Recht?, 2003, pp. 55-59.

32 HOFFMANN-RIEM, W., "Enge oder weite Gewährleistungsgehalte der Grundrechte?", BAUERLE (ed), Haben wir wircklich Recht?, 2003, pp. 62-65.

33 HOFFMANN-RIEM, W., "Enge oder weite Gewährleistungsgehalte der Grundrechte?", BAUERLE (ed), Haben wir wircklich Recht?, 2003, pp. 71-75.

34 KAHL, W, "Vom weiten Schutzbereich zum engen Gewährleistungsgehalt", Der Staat 2004, pp. 167-169. 
definitiva, de ámbitos de protección tradicionalmente amplios a contenidos de garantía reducidos. Así, por ejemplo, para el Bundesverfassungsgericht, afirmaciones de hechos ciertas no pueden vulnerar el libre despliegue de la personalidad (artículo $2 \mathrm{LF}$ ), y ello se proyecta sobre el ciudadano que ve en una lista hecha pública por un Ministerio de un Land su nombre como miembro de una organización cienciológica. También destaca el denominado caso "Osho", denominación de un movimiento religioso: afirmaciones que le imputaban ser una secta no son consideradas por el Tribunal Constitucional como difamatorias, y por consiguiente no considera que atenten contra la libertad de fe y culto garantizada en el artículo 4 LF. El Bundesverfassungsgericht ha amparado, en relación con la libertad de opinión e información, hechos que aun siendo inciertos se encuentran inseparablemente unidos a juicios de opinión o son condición para la formación de opinión. Por último, sólo se vulnera la libertad de empresa a juicio del Tribunal Constitucional alemán si la competencia se limita de forma irrazonable; especialmente significativo es el caso "Glycoln, en el que se trataba de dilucidar si la publicación de una lista por el Ministerio de Sanidad alemán de los productores de vino contaminado con "Glycol" afectaba a la libre competencia; para el Bundesverfassungsgericht, el artículo que ampara el derecho a elegir libremente la profesión (artículo 12 LF) no protege frente a la divulgación de información objetiva en el mercado, aún cuando ésta pueda afectar a la competencia.

Se alega que la configuración de un ámbito de protección amplio incide en la multiplicación de los denominados límites inmanentes, no controlables racionalmente. Pero, a juicio de Kahl, precisamente la división del ámbito de protección en diferentes dimensiones, como postulan Böckenförde y HoffmannRiem, permite multiplicar las posibilidades de limitar los derechos ${ }^{35}$. Kahl entiende que el nuevo concepto de contenido de protección, con alcance reducido, trae causa de un concepto amplio de intervención en el derecho que solo conduce a la inseguridad y a la arbitrariedad. Él abogaría por restringir el ámbito de actuación que recibe la calificación de antervención en el derecho, ${ }^{36}$. Ahora, esta noción amplia de intervención se articula mediante la denominada ponderación, mediada por valoraciones subjetivas. Si el problema fundamental que padece la dogmática de los derechos fundamentales es la falta de seguridad jurídica, la nueva propuesta de Böckenförde no soluciona el problema, como el propio Böckenförde dejaba entrever ${ }^{37}$. La valoración y la ponderación se desplazan simplemente de la justificación de la intervención en

35 KAHL, W., "Vom weiten Schutzbereich zum engen Gewährleistungsgehalt", Der Staat 2005, pp. 181-183.

36 En un sentido parecido se pronuncian Pierrot y Schlink. Comprenden la extensión del concepto de intervención en el derecho, que trae causa de la propia evolución del Estado liberal al Estado social de Derecho. Pero esta extensión, a su juicio, no se encuentra exenta de peligros. Por eso parece necesario superarla, PIEROTH, B.; SCHLINK, B., Grundrechte. Staatsrecht II, Heilderberg: C.F. Müller, 2005, pp. 58-61.

37 Cfr. p. 313. 
el derecho al momento de determinar el ámbito de protección del mismo ${ }^{38}$. La determinación del contenido de garantía conduce, en definitiva, a la falta de racionalidad en el procesamiento de los derechos y a un nuevo positivismo jurisprudencial (del Tribunal Constitucional) que rompe con los clásicos principios del constitucionalismo ${ }^{39}$.

El problema, en el fondo, radica en una diferente concepción de las funciones del legislador. Para Kahl, éste no puede actuar como garante de los derechos: su específica consideración como "enemigo de los derechos fundamentales" impide otorgarle la facultad de configurar los derechos ${ }^{40}$. Éstos precisan de un "defensor", que es sin embargo el Tribunal Constitucional. Y éste debe emplear al contenido esencial de los derechos, indisponible para el legislador, para asumir esta tarea $a^{41}$

Hoffmann-Riem, frente a las críticas de Kahl, defiende que la evolución impuesta por las actuales sociedades a la dogmática de los derechos fundamentales puede ser compatible con la pretensión de racionalidad que debe ser inherente a esta dogmática. Porque, ciertamente, la crítica de Kahl parte de la falta de racionalidad a que conduce en la práctica la nueva dogmática. Para Hoffmann-Riem la evolución del significado, del sentido y de la naturaleza de los derechos en la historia del constitucionalismo incide lógicamente en su propia dogmática. Y hoy, en este sentido, se justifica la necesidad de diferenciar entre ámbito vital del derecho y contenido de garantía ${ }^{42}$. En primer lugar, a partir del propio sentido de la interpretación constitucional; en segundo término, por la necesidad de adecuar los derechos a los retos que impone la actual sociedad pluralista.

La apertura de la Constitución impide hablar de una única interpretación válida de la Constitución. Por ello, los esfuerzos deben ponerse en buscar el modo más racional posible de determinación del contenido de las normas constitucionales $^{43}$. Kahl considera que la configuración del legislador como conformador de los derechos pervierte el propio sentido de la ley. Para Hoffmann-Riem ${ }^{44}$, por el contrario, la condición del legislador, como intérprete privilegiado de la Constitución, le convierte en especialmente adecuado para configurar los derechos fundamentales y establecer sus límites; justamente el es-

38 KAHL, W., "Vom weiten Schutzbereich zum engen Gewährleistungsgehalt”, Der Staat 2005, pág 193.

39 KAHL, W., "Vom weiten Schutzbereich zum engen Gewährleistungsgehalt", Der Staat 2005, p. 195.

40 KAHL, W., "Vom weiten Schutzbereich zum engen Gewährleistungsgehalt", Der Staat 2005 , p. 201.

41 KAHL, W., "Vom weiten Schutzbereich zum engen Gewährleistungsgehalt", Der Staat 2005, págs 200, 2001.

42 HOFFMANN-RIEM, W., "Grundrechtsanwendung unter Rationalitätsanspruch. Eine Erwiderung auf Kahls Kritik an neueren Ansätzen in der Grundrechtsdogmatik", Der Staat, 2005, pp. 1-16.

43 HOFFMANN-RIEM, W., "Grundrechtsanwendung unter Rationalitätsanspruch. Eine Erwiderung auf Kahls Kritik an neueren Ansätzen in der Grundrechtsdogmatik", Der Staat, 2004, pp.224 ss.

44 HOFFMANN-RIEM, W., "Grundrechtsanwendung unter Rationalitätsanspruch. Eine Erwiderung auf Kahls Kritik an neueren Ansätzen in der Grundrechtsdogmatik", Der Staat, 2005, pp. 
tablecimiento de tales límites de forma general y abstracta mediante la ley asegura la racionalidad. Por lo demás, la proporcionalidad constituye un procedimiento racional de control, en última instancia, de tales limitaciones legislativas de los derechos ${ }^{45}$.

Los nuevos retos y peligros que la actual sociedad pluralista proyecta sobre la realización efectiva de los derechos fundamentales, como había señalado anteriormente el propio autor, hacen también imprescindible la participación del legislador para coordinar intereses en la garantía de los derechos ${ }^{46}$; y para ello sirve la nueva distinción entre ámbito vital y contenido de garantía, siendo en este último donde el legislador encuentra un espacio adecuado para realizar su tarea. Sin la participación del legislador, determinando el contenido de garantía del derecho, peligra seriamente la normatividad de los derechos fundamentales.

\section{RECAPITULACIÓN}

La contraposición característica del Estado constitucional, esto es, la suma y la tensión entre el legislador democrático y los derechos de la persona, no deja de suscitar polémicas en el vigente constitucionalismo ${ }^{47}$. Ciertamente, "lo esencial para la realización de los Derechos fundamentales debe y puede ser obra del legislador, en la misma medida en que él mismo puede amenazar también la libertad ${ }^{48}$. El reto consistirá en saber atribuir a cada uno de estos aspectos el peso específico que le corresponde en el vigente constitucionalismo.

Los riesgos que derivan de atribuir a la jurisdicción constitucional más peso del que le compete han sido señalados por Böckenförde; la diferenciación entre ámbito material y vital del derecho y contenido de garantía se orienta en esta dirección; al limitar la imposición de los denominados límites inmanentes otorga al legislador un papel central en la configuración del contenido de garantía del derecho. El nuevo papel que corresponde al legislador dota a esta diferenciación dogmática de especial interés también para los defensores de la dimensión objetiva de los derechos fundamentales; así se explica que sea asumida por Hoffmann-Riem, quien ve en esta distinción la posibilidad de justificar y extender el papel del legislador en la configuración de los derechos,

45 HOFFMANN-RIEM, W., "Grundrechtsanwendung unter Rationalitätsanspruch. Eine Erwiderung auf Kahls Kritik an neueren Ansätzen in der Grundrechtsdogmatik", Der Staat, 2005, págs 231, 232.

46 HOFFMANN-RIEM, W., "Grundrechtsanwendung unter Rationalitätsanspruch. Eine Erwiderung auf Kahls Kritik an neueren Ansätzen in der Grundrechtsdogmatik", Der Staat, 2005, págs 227, 228, 229.

47 Cfr. CRUZ VILLALÓN, P., "El legislador de los derechos fundamentales", LÓPEZ PINA, A (ed), La garantía constitucional de los derechos fundamentales. Alemania, España, Francia e Italia, Madrid: Cívitas, 1991, pp. 125 y ss.

48 HÄBERLE, P., "Contenidos significativos y funciones de la ley parlamentaria", LÓPEZ PINA, A. (ed), Democracia representativa y parlamentarismo. Alemania, España, Gran Bretaña e Italia, Madrid: senado, 1994, p. 76. 
algo absolutamente necesario para asegurar su normatividad en la actual sociedad pluralista. La nueva dogmática ofrece también respuesta a las múltiples colisiones entre derechos, que solo cabe resolver mediante normas específicas, no con reglas abstractas y generales contenidas en la Constitución.

La dogmática clásica, defendida por Kahl, pretende garantizar mayor racionalidad: ofrece una nítida diferenciación entre los derechos, cuyo protector es el Tribunal Constitucional por medio de su contenido esencial, y el legislador, que proyecta la democracia, y es enemigo de aquéllos. Tal dogmática de los derechos, si quiere asegurar la propia apertura de la Constitución, debe delimitar al mismo tiempo las posibilidades que tiene el Tribunal Constitucional de controlar al legislador; pues el control se basa ahora, en realidad, en criterios, al menos a su juicio, no controlables racionalmente. Sin embargo, la pretensión de certeza, como observa Grimm, tampoco se consigue plenamente en el constitucionalismo clásico; un cierto margen de inseguridad se produce también en tal dogmática ${ }^{49}$. La relatividad de la razón y la objetividad son inseparables del razonamiento jurídico.

En definitiva, la orientación fundamental de este debate parece abocar a una comprensión reductiva del contenido esencial de los derechos, y a otorgar al legislador una amplia capacidad de configuración de los mismos. La participación del legislador en la conformación de los derechos abre la dogmática a los nuevos retos que impone la actual sociedad. Pero no puede olvidarse que el legislador de los derechos debe estar, al menos parcialmente, determinado por la Constitución. Esa es la nota que individualiza mejor a los derechos fundamentales y que debe ser desarrollada en el marco del constitucionalismo social.

ABSTRACT. In Germany has recently show up a debate over the content of rights, it's also a debate over the interpretation wide or restrictive of the protection of rights, that includes the principle of proporcionality and the nature of the essential content of rights. Hoffmann-Riem assumes Böckenförde's proposal of separating vital concept of rights, protection content of rights and limitates of rights, but with several grounds. Kabl reject this proposal in order to defend a classic dogmatic of rights, which is the only one, Kabl assumes, can offer security.

49 GRIMM, D., "Rückker zum liberalen Grundrechtverständnis?, Die Zukunft der Verfassung, Frankfurt am Main: Suhrkamp Verlag, 1991, pp. 235-237 (existe versión al castellano realizada por Raúl Sanz Burgos y José Luis Muñoz de Baena, Constitucionalismo y derechos fundamentales. Estudio preliminar de Antonio López Pina, Madrid: Trotta, 2006). 